\title{
¿Estudiando el Desarrollo Embrionario y Fetal con el Microscopio Virtual! En Tiempos de Covid-19
}

\author{
Studying Embryonic and Fetal Development with the \\ Virtual Microscope! In the Times of Covid-19 \\ Mariana Rojas'; Fabrizio Cuevas'; Carolina Smok²; Ignacio Roa \\ Daniel Conei ${ }^{4}$; Ruth Prieto ${ }^{5}$ \& Mariano del Sol ${ }^{6}$
}

ROJAS, M.; CUEVAS, F.; SMOK, C.; ROA, I.; CONEI, D.; PRIETO, R. \& DEL SOL, M. ;Estudiando el desarrollo embrionario y fetal con el microscopio virtual! En tiempos de covid-19. Int. J. Morphol., 38(5):1296-1301, 2020.

RESUMEN: La Microscopía Virtual es una herramienta tecnológica que permite la visualización de imágenes digitales microscópicas de gran resolución a través de un computador imitando la funcionalidad de un microscopio óptico tradicional. El presente trabajo presenta nuestra experiencia en el uso de esta modalidad de trabajo, útil hoy en día, en medio de la pandemia por Covid-19.

PALABRAS CLAVE: Embriología; Docencia; Microscopio virtual.

\section{INTRODUCCIÓN}

La Microscopía Virtual es una herramienta tecnológica que permite la visualización de imágenes digitales microscópicas de gran resolución, a través de un computador, imitando la funcionalidad de un microscopio óptico tradicional (Briones, 2016). El desarrollo tecnológico de áreas como la microscopía y las tecnologías de la información (TIC), han permitido el desarrollo de microscopios escaneadores de tejido para digitalizar placas histológicas completas. El proceso de escaneado genera un archivo digital llamado Whole Slide Imaging (WSI) o placa virtual, las cuales corresponden a un archivo con estructura de datos piramidal, donde la base de la pirámide está compuesta de imágenes organizadas como bloques contiguos de imágenes de alta resolución, para formar una imagen final completa, visible desde el vértice de la pirámide con menor magnificación y menor resolución. Éstas imágenes tienen un gran tamaño, sin embargo gracias al uso de las plataformas on line de MV se pueden visualizar, navegar y anotar a través de internet (Triola \& Holloway, 2011) utilizando un software visualizador que emula el comportamiento de un microscopio óptico convencional (Chiu et al., 2014).
La Docencia de Embriología se realiza mediante clases teóricas y actividades prácticas en las cuales se observan embriones y fetos mediante lupa estereoscópica, y además cortes histológicos que se analizan al microscopio óptico. La gran problemática es el insuficiente tiempo que los estudiantes poseen para internalizar, comparar, analizar, describir por sí mismos las imágenes histológicas, careciendo en este análisis además de longitudes y áreas de las estructuras, importantes para comprender el total. Previamente se han realizado trabajos con MV aplicados a la docencia (Dee, 2009), enseñanza de la Patología (Hamilton et al., 2012), e Histología (Paulsen et al., 2010), sin embargo hasta el año 2019 no ha sido utilizada masivamente.

Las actuales crisis sociales y de salud por la pandemia de Covid-19, han impactado fuertemente nuestros tiempos destinados al proceso de enseñanza-aprendizaje, viéndose las universidades cerradas y en la necesidad de implementar docencia a distancia. Sumado a esto nuestros estudiantes de regiones no pueden asistir a clases sincrónicas por problemas de salud y de banda ancha o internet. La MV permite

\footnotetext{
${ }^{1}$ Programa de Anatomía y Biología del Desarrollo, ICBM, Facultad de Medicina Universidad de Chile, Santiago, Chile.

${ }^{2}$ Universidad Central de Chile, Santiago, Chile.

${ }^{3}$ Unidad de Morfología, Depto de Ciencias Básicas Biomédicas, Facultad de Ciencias de la Salud, Universidad de Talca, Talca, Chile.

${ }^{4}$ Departamento de Ciencias de la Salud, Universidad de Aysén, Coyhaique, Chile.

${ }^{5}$ Departamento de Pediatría y Cirugía Infantil, Facultad de Medicina, Universidad de La Frontera, Temuco, Chile.

${ }^{6}$ Centro de Excelencia en Estudios Morfológicos y Quirúrgicos (CEMyQ), Universidad de La Frontera, Temuco, Chile.
} 
así a los diversos estudiantes acceder, cuando lo deseen y lo necesiten, a los preparados histológicos y embriológicos desde sus hogares. Además estos contenidos pueden ser descargados en cualquier momento, cambiar aumentos, recorrer los preparados, medir áreas, longitudes y perímetros.

El objetivo del presente estudio fue describir la Microscopía Virtual como una herramienta útil tanto para morfólogos como para estudiantes en el estudio del desarrollo embrionario y fetal.

\section{MATERIAL Y MÉTODO}

Preparación y Digitalización de cortes histológicos. Se realizaron preparados histológicos con cortes seriados de embriones de pollo (Gallus gallus domesticus) de $40 \mathrm{~h}$ de incubación, así como un feto humano de 12 semanas aproximadas post fecundación, perteneciente a la colección de preparados embriológicos de la Facultad de Medicina, Universidad de Chile.

Los preparados histológicos fueron escaneados y digitalizados utilizando un microscopio NanoZoomer XR C12000 series (Hamamatsu Photonics, Hamamatsu, Japón). obteniéndose archivos en formato WSI, los cuales fueron alojados en la plataforma virtual http:// ndp.microscopiavirtual.com, a la cual tanto el estudiante como docente poseen acceso mediante el ingreso de nombre usuario y password. Las imágenes fueron organizadas en base a objetivos de aprendizaje, en esta plataforma los usuarios pueden navegar a través de las imágenes mediante el uso del software on line NDP (NanoZoomer Digital Pathology) viewer 2.0 (Hamamatsu Photonics, Hamamatsu, Japón).

Ingresando al microscopio virtual. Ingresar a http:// ndp.microscopiavirtual.com, luego escribir en username: alumno-obs2020 y la clave: obsfisiol2020. Hacer un click en sign in, y la carpeta Browse images, después presionar Facultad de Medicina y por último la carpeta que dice Obstetricia Fisiológica. A continuación la carpeta que señala paso práctico 2 y luego el preparado que dice 362-PABD-1-AD2018. Cortes seriados de embrión de pollo. Después revisar el preparado feto humano. Puede rotar la imagen presionando la flecha verde- y colocar mayor aumento haciendo un click en el ocular (ver la flecha roja. (Fig. 1).

Observando las imágenes de desarrollo de riñón con microscopía virtual. Veremos como ejemplo, el trabajo práctico que corresponde al desarrollo de riñón. El objetivo es que el estudiante pueda reconocer dos tipos de riñones: mesonefros y metanefros los cuáles aparecen en distintos
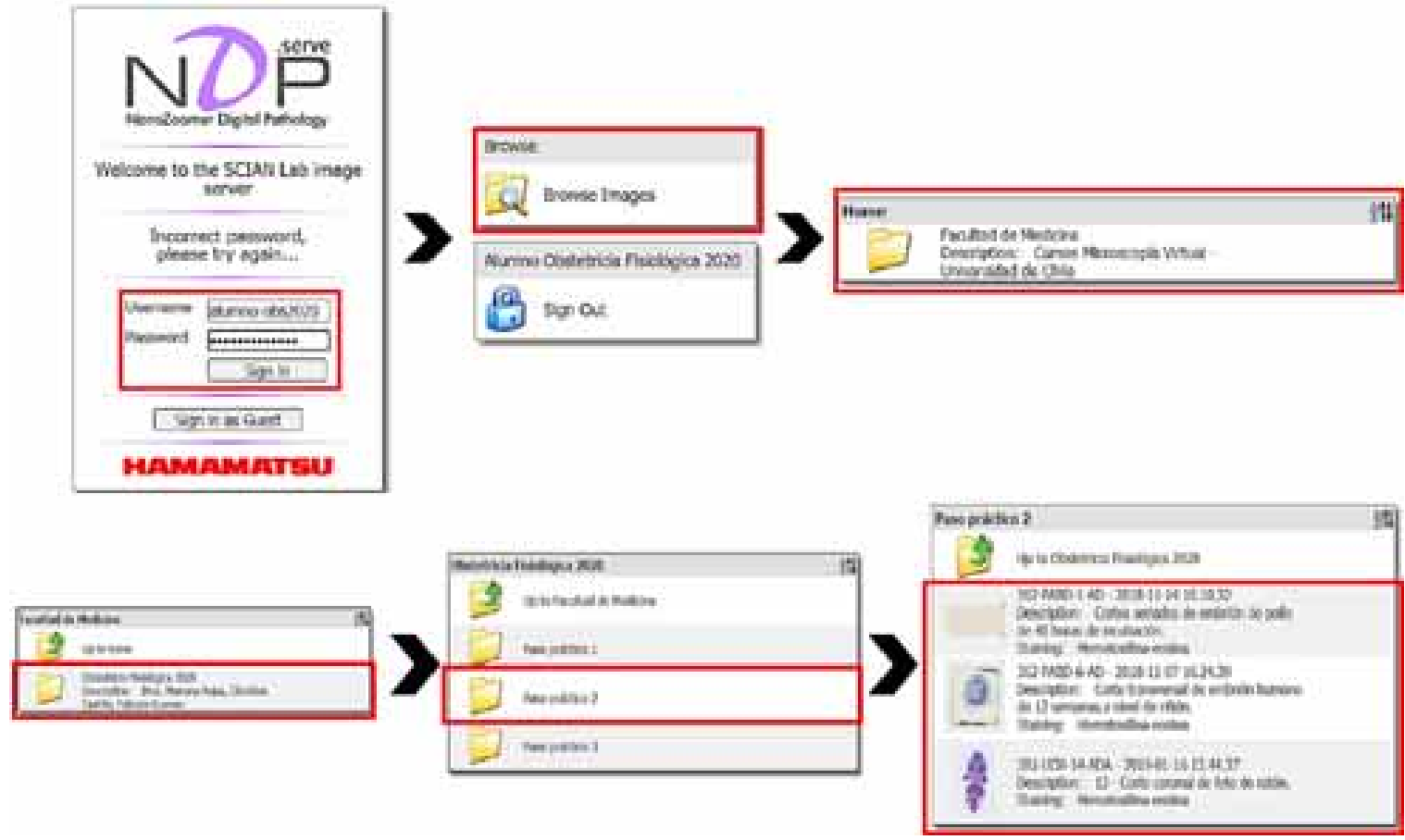

Fig. 1. Ingresar a http://ndp.microscopiavirtual.com, luego escribir en username: alumno-obs2020 y en pasword escribir bdeh-alumno-obs. luego hacer click en sign in. Después presiona la carpeta Browse images. Presiona Facultad de Medicina y por último la carpeta que dice Obstetricia Fisiológica. Presiona la carpeta que dice paso práctico 2 y luego presiona los preparados embrión de pollo y feto humano. 
momentos del desarrollo humano, tienen distinta ubicación (torácica y lumbar-sacra) y presentan una morfología que va siendo cada vez más compleja. El segundo objetivo es que el alumno pueda explicar cuál es el origen y el destino de la yema ureteral y del blastema metanéfrico y que los reconozca en las imágenes histológicas.

Para cumplir con el primer objetivo se utiliza un corte transversal de un embrión de pollo (362 PABD-1AD), comparable con un embrión humano de quinta semana, con el fin de analizar el mesodermo intermedio. En el mesodermo intermedio se puede reconocer el mesonefros que es un riñón transitorio y que está formado por un conducto mesonéfrico, túbulos mesonéfricos y corpúsculos renales muy incipientes que no han completado su formación (Fig. 2), similar a lo descrito por Dressler (2006). El conducto mesonéfrico crece en dirección caudal hasta desembocar en el seno urogenital (futura vejiga).

Para complementar el segundo objetivo utilizamos el preparado que corresponde al corte transversal de feto humano de 12 semanas (362-PABD-6-AD). En este preparado se observa el riñón definitivo o metanefros el cual se forma a partir de interacciones entre una evaginación del conducto mesonéfrico, correspondiente a la yema ureteral y el mesodermo intermedio que a nivel lumbo-sacro se condensa, formando el blastema metanéfrico similar a lo indicado por (Little \& McMahon, 2012).

En este preparado el blastema metanéfrico se distingue muy bien por su tinción de color celeste, debido a que el azul de Alcián destaca los glicosaminoglicanos. Se puede reconocer la formación de nefronas menos desarrolladas en su zona periférica y más grandes y maduras cerca de la futura médula (Fig. 3). La formación de nefronas empieza con la formación de los túbulos renales, a partir de condensaciones del mesénquima del blastema metanéfrico que rodea a las ampollas de conductos colectores (Fig. 4). Esto sucede gracias a interacciones inductivas recíprocas entre las ampollas de los conductos colectores y las células del blastema metanéfrico situadas alrededor de ellas. Los conductos colectores inducen la formación de los túbulos renales, de la misma

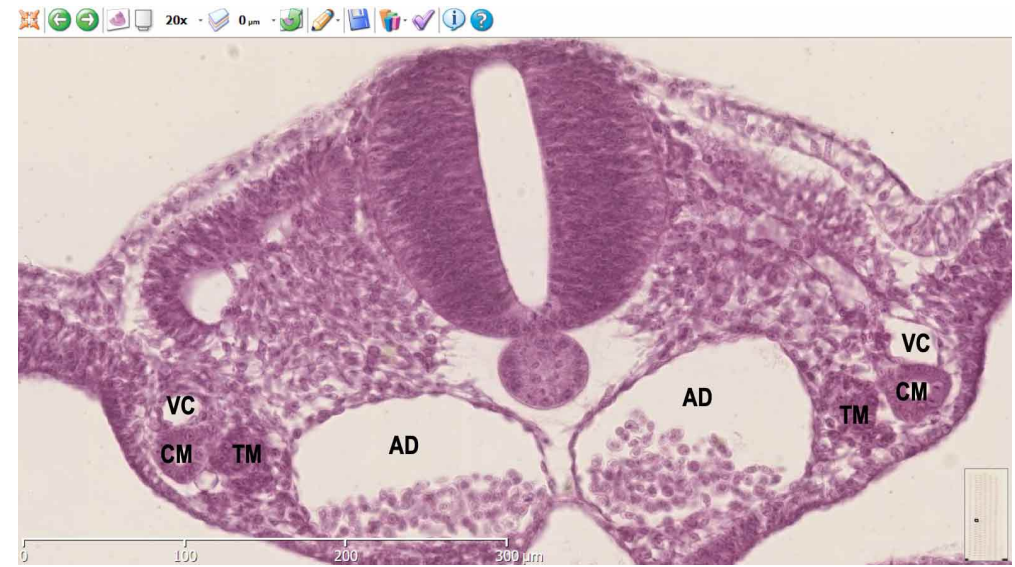

Fig. 2. Formación del mesonefros. Se observa conducto mesonéfrico (CM), y el inicio de la formación de los túbulos mesonéfricos (TM), venas cardinales (VC) aorta dorsal (AD). Corte transversal de un embrión de pollo. 200X. Tinción H-E.

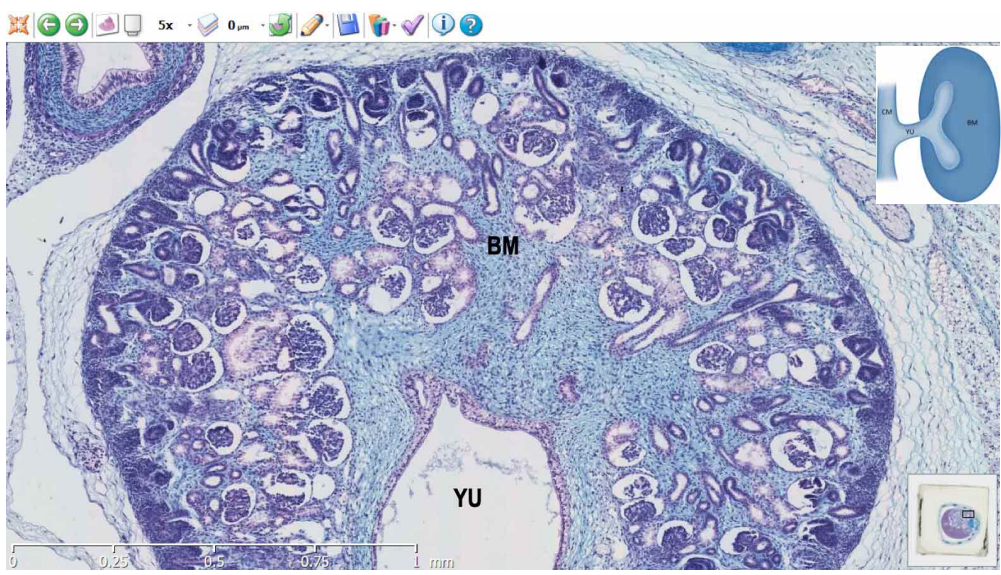

Fig. 3. Formación del metanefros. Corte transversal de feto de 12 semanas post fecundación. Se observa la formación de las nefronas, las etapas mas indiferenciadas están en la periferia de la corteza y las más maduras hacia la médula. La pelvis es un derivado de la yema ureteral. Aun no está el riñón totalmente constituído. 50X H-E-Azul de Alcián. En el recuadro se ve los orígenes del riñón que son la yema ureteral (YU)y el blastema metanéfrico(BM).

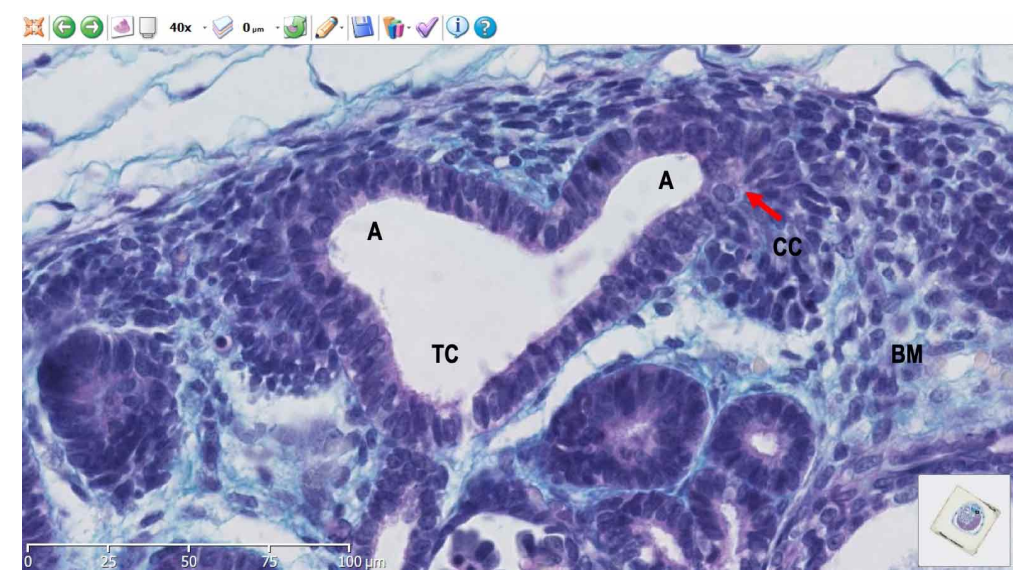

Fig. 4. Formación de la nefrona. Los tubos colectores (TC) son derivados de la yema ureteral y se bifurcan en dos ampollas (A). Desde el blastema metanéfrico (BM) ocurre la condensación celular (CC) en las zonas relacionadas con las ampollas (flecha roja). 400X H-E azul de Alcián 
manera que el blastema metanefrogénico actúa sobre los conductos colectores para inducir su ramificación típica.

Posteriormente las células mesenquimales condensadas del blastema forman el primordio del túbulo renal y adoptan forma de coma, luego un grupo de células se polariza, formando una luz central y una lámina basal (Fig. 5) esto ocurre mediante un mecanismo biológico conocido como transformación mesénquima-epitelial. El mesénquima metanéfrico que ha sido inducido, estimula el crecimiento de células endoteliales, que están conectadas con ramas de la aorta dorsal y se convierten en el glomérulo. Luego el túbulo renal se transforma en una estructura similar a una S (Fig. 6). Las células del resto del primordio tubular también pasan por una transformación epitelial para dar lugar al resto del túbulo renal. En la nefrona se ha diferenciado la cápsula glomerular y el espacio urinario a las 12 semanas p.f (Fig. 6 y 7).

De esta manera el divertículo ureteral proviene del conducto mesonéfrico y llegará a formar uréter, pelvis, cálices mayores, cálices menores y tubos colectores, en tanto que el blastema metanéfrico se forma a partir del mesénquima que rodea al divertículo ureteral y originará la nefrona formada por corpúsculo renal, túbulo renales, estos últimos posteriormente se van a diferenciar en contorneado proximal, asa renal (asa de Henle) y tubo contorneado distal.

Durante la etapa fetal, los riñones no se encargan de la excreción de productos de desecho, porque ese rol lo tiene la placenta. Sin embargo, son funcionales desde la $12^{\circ}$ semana p.f. (Dressler, 2009). La orina que producen (contiene factores de crecimiento) pasa a la cavidad amniótica donde se mezcla con el líquido amniótico. Este líquido es deglutido por el feto y va a los pulmones y al intestino para gatillar la diferenciación y maduración de sus respectivos epitelios. Además el volumen del LA se mantiene a través de un balance entre la producción de líquido fetal (orina) y su reabsorción (deglución fetal y el flujo a través de las membranas hacia el feto o la madre). Cuando se producen alteraciones en la formación del riñón, puede

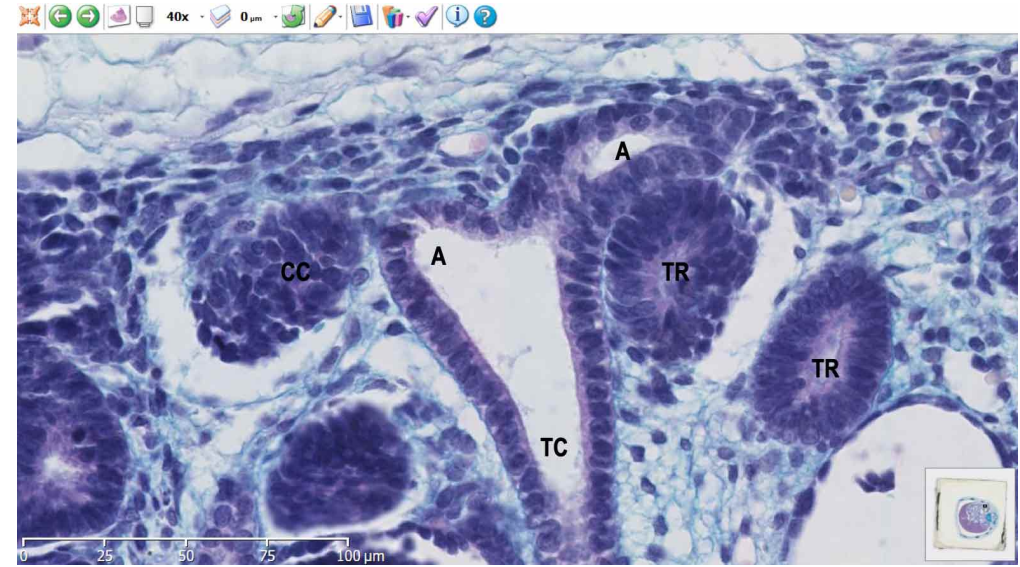

Fig. 5. Formación de la nefrona. Las condensaciones celulares (CC)se transforman en túbulos renales (TR) y se alargan por un proceso de transformación mesénquima epitelial. Tubos colectores (TC), ampollas (A). 400X. H-E azul de Alcián.

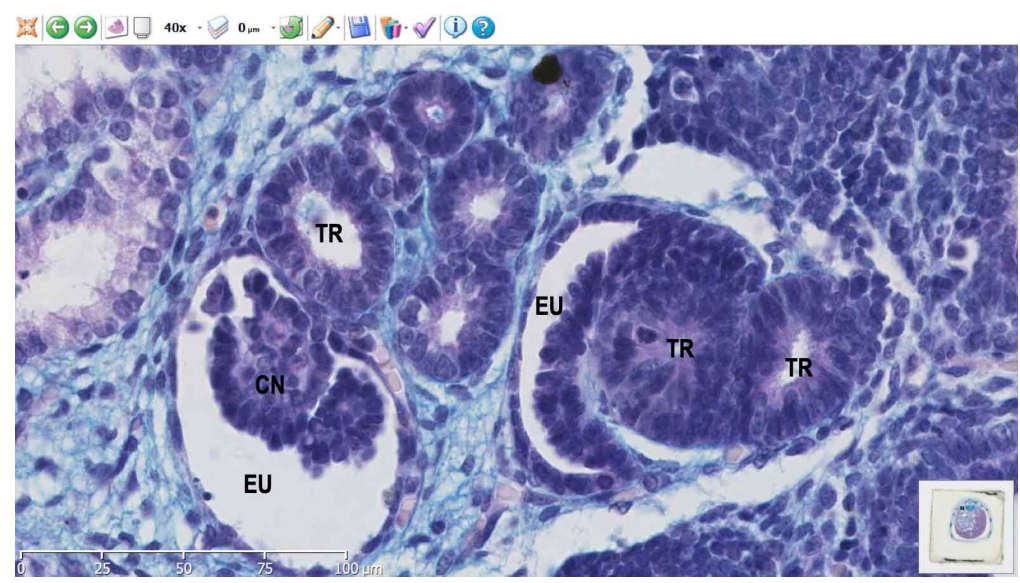

Fig. 6. Elongación del túbulo renal. El túbulo renal (TR) se elonga, se dobla en $\mathrm{S}$ y empieza a formar el corpúsculo néfrico $(\mathrm{CN})$, con su respectivo espacio urinario (EU). 400X. H-E azul de Alcián.

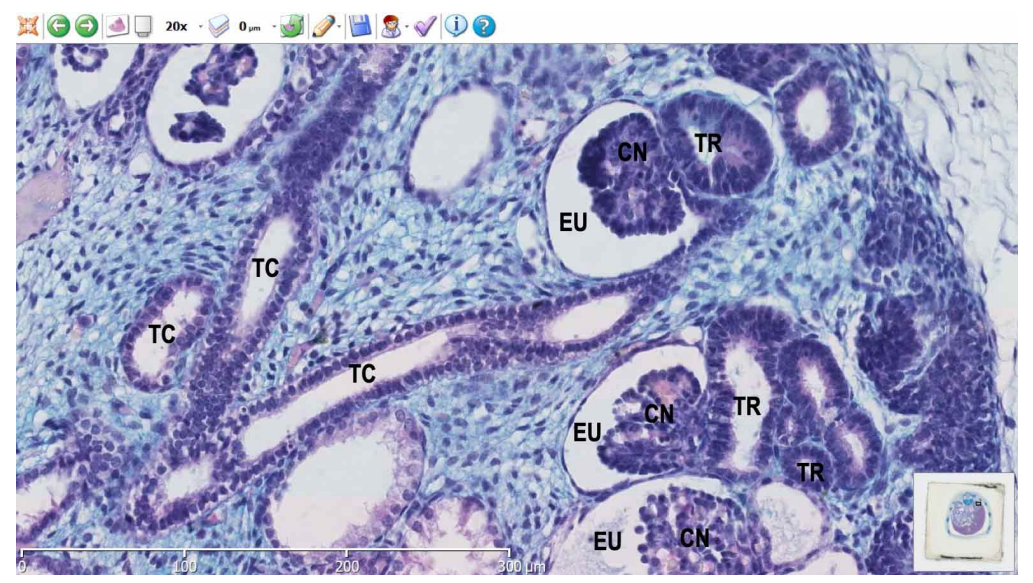

Fig. 7. En el blastema metanefrogénico (color celeste) se ven los corpúsculos néfricos $(\mathrm{CN})$ con su espacio urinario (EU). Los túbulos renales (TR) están bien constituidos, pero no se han diferenciado en los segmentos de la nefrona. Los derivados del divertículo ureteral como tubos colectores (TC) también se observan. 200X.Tinción H-E-azul de Alcián. 
ROJAS, M.; CUEVAS, F.; SMOK, C.; ROA, I.; CONEI, D.; PRIETO, R. \& DEL SOL, M. ¡Estudiando el desarrollo embrionario y fetal con el microscopio virtual! En tiempos de covid-19. Int. J. Morphol., 38(5):1296-1301, 2020.

Tabla I. Artículos complementarios que apoyan la docencia tanto de Embriología Humana como de Embriología Veterinaria.

\begin{tabular}{|c|c|c|c|}
\hline Nombre del artículo & Autores & Revista & Año \\
\hline $\begin{array}{l}\text { Malformaciones congénitas: aspectos generales y } \\
\text { genéticos }\end{array}$ & $\begin{array}{l}\text { Rojas } \\
\text { Walker }\end{array}$ & $\begin{array}{l}\text { Int. J. Morphol., 30(4):1256-1265, } 2012 . \\
\text { http://dx.doi.org/10.4067/S0717- } \\
\text { 95022012000400003 }\end{array}$ & 2012 \\
\hline Modelando el cuerpo durante el período somítico & $\begin{array}{l}\text { Rojas } \\
\text { Smok }\end{array}$ & Int. J. Med. Surg. Sci., 1(1):57-62. 2014. & 2014 \\
\hline Desarrollo fetal en mamíferos & $\begin{array}{l}\text { Smok; Roa \& } \\
\text { Rojas }\end{array}$ & Int. J. Med. Surg. Sci, 1(2):139-145, 2014. & 2014 \\
\hline $\begin{array}{l}\text { Morfógenos durante el desarrollo embrionario de } \\
\text { vertebrados }\end{array}$ & $\begin{array}{l}\text { Rojas; } \\
\text { Signore } \\
\text { Mejías }\end{array}$ & $\begin{array}{l}\text { Int. J. Morphol., 32(1):319-326, } 2014 . \\
\text { http://dx.doi.org/10.4067/S0717- } \\
\text { 95022014000100051 }\end{array}$ & 2014 \\
\hline $\begin{array}{l}\text { Efectos del tratamiento con vitamina } \mathrm{E} \text { en el tubo } \\
\text { neural y médula espinal en embriones y fetos de } \\
\text { ratones } M \text { us musculus expuestos al uso de ácido } \\
\text { valproico }\end{array}$ & $\begin{array}{l}\text { Conei; Soler; } \\
\text { Saint-Pierre; } \\
\text { Ortiz \& Rojas }\end{array}$ & $\begin{array}{l}\text { Int. J. Morphol., 34(2):732-741, } 2016 . \\
\text { http://dx.doi.org/10.4067/S0717- } \\
95022016000200049\end{array}$ & 2016 \\
\hline $\begin{array}{l}\text { Transitando de embrión a feto: la metamorfosis de } \\
\text { los cordados }\end{array}$ & $\begin{array}{lr}\text { Smok; } & \text { Roa; } \\
\text { Prieto } & \& \\
\text { Rojas } & \end{array}$ & $\begin{array}{l}\text { Int. J. Morphol., } \\
\text { http://dx.doi.org/10.4067/S0717- } \\
95022018000200709\end{array}$ & 2018 \\
\hline
\end{tabular}

haber oligohidramnios y la enfermedad de Potter, la que cursa con hipoplasia pulmonar (Little \& McMahon).

Material de apoyo. Se desarrollaron clases y tutoriales con audio en forma de cápsulas de 10 minutos, colocadas en aula digital de la Universidad de Chile y en: https:// youtube.com/channel/UC8FPUaeeBcYokJws RiloPEA? view_as=subscriber - además se complementa con un artículo que se puede bajar de internet. (Lemus et al., 2015). El desarrollo de la actividad práctica se realiza en conjunto con una serie de artículos que apoyan la docencia en Embriología humana y veterinaria (Rojas \& Walker, 2012; Rojas et al., 2014; Rojas \& Smok, 2014; Smok et al., 2014; Conei et al., 2016; Smok et al., 2018) (Tabla I).

\section{CONCLUSIÓN}

La Microscopía Virtual resulta ser una valiosa herramienta en la actualidad, donde en los últimos meses nos hemos enfrentado a la pandemia de Covid-19. Las medidas de confinamiento dentro de nuestros hogares, nos han obligado a realizar en estos casos teletrabajo, comunicándonos con nuestros estudiantes de manera virtual; por lo cual esta herramienta, que ya ha sido probada anteriormente, vino a solucionar la problemática de la presencialidad del estudiante/docente en el laboratorio. Concordamos con las opiniones de Briones en que la Microscopía Virtual resuelve en gran medida problemas inherentes de la microscopía convencional, como por ejemplo: i) acceso limitado a microscopios, ii) escaso tiempo de contacto entre estudiantes y el material de trabajo. Otor- gando acceso en todo momento y lugar a la actividad práctica, tanto al estudiante, como al docente.

El uso de placas histológicas virtuales permite además, que todos los estudiantes puedan trabajar con la misma imagen a la vez, visualizando en la plataforma una vista general de la placa virtual en miniatura, con referencias a la posición dentro de ella, indicándonos el nivel de magnificación. La Microscopía Virtual nos permite observar los embriones de manera mesoscópica con aumentos de $1.2 \times, 2,5 \times, 5 \times, 10 \times, 20 \times$, ventaja que nos permite visualizar la totalidad del preparado en el mismo campo visual, lo cual no es posible en los microscopios convencionales; esta posibilidad facilita la ubicación espacial, característica esencial para el estudio de la embriología (Hamilton et al.). También es interesante la reglilla graduada en micrones y milímetros y la posibilidad de medir las estructuras longitudes, áreas y perímetros, lo cual le permite al estudiante realizar comparación de estructuras.

Los estudiantes de las carreras del área salud de la Universidad de Chile, han tenido acceso a esta metodología, como refuerzo al método tradicional presencial, método que este año 2020 será fundamental y único para que ellos puedan avanzar, en el contexto de una pandemia por coronavirus (Covid-19), que ha afectado fuertemente a la ciudad de Santiago como al resto del país.

Utilizar repositorios virtuales con el fin de poner a disposición de los estudiantes y docentes en sus plataformas universitarias el material de las actividades prácticas, resulta, a nuestro parecer, ser beneficioso para la práctica actual de la histo-embriología, dándole al estudiante, la 
libertad de observar y describir las estructuras; y al académico, las facilidades de nuevos aportes al conocimiento del desarrollo embriofetal más allá de los programas de estudio convencionales.

\section{AGRADECIMIENTOS}

A Susana Vargas, Tecnólogo Médico, quien realizó las digitalizaciones de los preparados embriológicos para Microscopía Virtual.

ROJAS, M.; CUEVAS, F.; SMOK, C.; ROA, I.; CONEI, D.; PRIETO, R. \& DEL SOL, M. Studying embryonic and fetal development with thvirtual microscope! in the times of Covid-19 Int. J. Morphol., 38(5):1296-1301, 2020.

SUMMARY: Virtual Microscopy is a technological tool that allows the visualization of high resolution microscopic digital images through a computer, imitating the functionality of a traditional light microscope. The present work presents our experience in the use of this working modality, useful today, in the midst of the Covid-19 pandemic.

KEY WORDS: Embryology; Teaching; Virtual microscope.

\section{REFERENCIAS BIBLIOGRÁFICAS}

Briones, L. M. Diseño e implementación de una Plataforma de Microscopía Virtual para Apoyar Docencia Universitaria. Tesis para optar al Grado de Magister en Informática Médica. Santiago de Chile, Facultad de Medicina, Universidad de Chile, 2016.

Chiu, B. K.; Solez K. \& Sergi C. M. Digital pathology for E-Learning and digital education - A Review. J. Inf. Technol. Appl. Educ., 3(4):164-8, 2014.

Conei, V. D.; Soler, G. B., Saint-Pierre, C. G.; Ortiz, C. J. \& Rojas, R. M. Efectos del tratamiento con vitamina $\mathrm{E}$ en el tubo neural y médula espinal en embriones y fetos de ratones Mus musculus expuestos al uso de ácido valproico. Int. J. Morphol., 34(2):732-41, 2016.

Dee, F. R. Virtual microscopy in pathology education. Hum. Pathol., 40(8):1112-21, 2009.

Dressler, G. R. Advances in early kidney specification, development and patterning. Development., 136(23):3863-74, 2009.

Dressler, G. R. The cellular basis of kidney development. Annu. Rev. Cell. Dev. Biol., 22:509-29, 2006.

Hamilton, P. W.; Wang Y. \& McCullough, S. J. Virtual microscopy and digital pathology in training and education. Apmis, 120(4):305-15, 2012.

Lemus, L.; Fuenzalida, M. \& Rosas, C. Desarrollo del aparato urinario. Int. J. Med. Surg. Sci., 2(2):447-54, 2015.

Little, M. H. \& McMahon, A. P. Mammalian Kidney Development: Principles, Progress, and Projections. Cold Spring Harb. Perspect. Biol., 4(5):a008300, 2012.

Paulsen, F. P.; Eichhorn, M. \& Bräuer, L. Virtual microscopy-The future of teaching histology in the medical curriculum? Ann. Anat., 192(6):378-82, 2010.
Rojas, M.; Signore, I. A. \& Mejías, R. Morfógenos durante el desarrollo embrionario de vertebrados. Int. J. Morphol., 32(1):319-26, 2014.

Rojas, M. \& Smok, C. Modelando el cuerpo durante el período somítico. Int. J. Med. Surg. Sci.,1(1):57-62, 2014.

Rojas, M. \& Walker, L. Malformaciones congénitas: aspectos generales y genéticos. Int. J. Morphol., 30(4):1256-65, 2012.

Smok, C.; Roa, I. \& Rojas, M. Desarrollo fetal en mamíferos. Int. J. Med. Surg. Sci., 1(2):139-45, 2014.

Smok, C.; Roa, I.; Prieto, R. \& Rojas, M. Transitando de embrión a feto: la metamorfosis de los cordados. Int. J. Morphol., 36(2):709-15, 2018.

Triola, M. M. \& Holloway, W. J. Enhanced virtual microscopy for collaborative education. BMC Med. Educ., 11:4, 2011

Dirección de correspondencia:

Dra. Mariana Rojas R.

Laboratorio de Embriología Comparada

Programa de Anatomía y Biología del Desarrollo

Facultad de Medicina, ICBM

Universidad de Chile

Santiago - CHILE

\section{Email: dramrojas@hotmail.com} mrojasr@u.uchile.cl

Recibido : 26-04-2020

Aceptado: 18-05-2020 